\title{
DIFFERENTIAL SUBCELLULAR LOCALIZATION OF TUBULIN AND THE MICROTUBULE-ASSOCIATED PROTEIN MAP2 IN BRAIN TISSUE AS REVEALED BY IMMUNOCYTOCHEMISTRY WITH MONOCLONAL HYBRIDOMA ANTIBODIES ${ }^{1}$
}

\author{
ALFREDO CACERES, ${ }^{*}, 2$ LESTER I. BINDER,§ MICHAEL R. PAYNE, $\S^{3}$ PATRICK BENDER, $\S$ \\ LIONEI, REBHUN,§ AND OSWALD STEWARD* ${ }^{4}$
}

Departments of ${ }^{*}$ Neurosurgery, $\ddagger$ Physiology, and $§$ Biology, University of Virginia, Charlottesville, Virginia 22908

Received February 16, 1983; Revised July 11, 1983; Accepted July 12, 1983

\begin{abstract}
The distribution and subcellular localization of tubulin and MAP2 in brain tissue were analyzed by immunocytochemistry with monoclonal hybridoma antibodies prepared against Chinese hamster brain tubulin and MAP2. We examined three anti-tubulin hybridoma antibodies (Tu3B, Tu9B, Tu12) specific for $\beta$-tubulin, and two anti-MAP2 hybridoma antibodies (AP9, AP13). The specificity of each of the monoclonal antibodies was characterized by staining nitrocellulose electrophoretic blots of SDS-polyacrylamide gels of whole brain or hippocampal extracts. Each hybridoma antibody bound only its respective antigen in these preparations. Polyclonal antisera against tubulin were also examined. Sections reacted with antisera against tubulin or monoclonal antibodies against $\beta$ tubulin revealed a wide variety of stained cellular compartments. The reaction product was found to decorate dendritic and axonal microtubles in neurons; glial cells were also stained. MAP2 immunoreactivity was found only in neurons. In the case of one of the monoclonal antibodies (AP9), staining was preferentially associated with dendritic processes. However, light but significant staining of axonal processes was seen with AP13. Within dendrites, MAP2 was found associated with dendritic microtubules and postsynaptic densities (psd), both in shaft and spine synapses. In addition, strong immunoreactivity for MAP2 was found within the cytoplasm of dendritic spines. There was little or no immunoreactivity for tubulin in the spine cytoplasm, although the psd was stained. The localization of MAP2 in dendritic spines and in the psd suggests that this protein may have a biological role independent of its association with microtubules. The observations on differential staining of the hybridoma antibodies against MAP2 suggest that there may be distinct subtypes or states of MAP2 within neurons.
\end{abstract}

Since the earliest observations of neurons stained by the Golgi technique, it has been apparent that neurons exhibit specializations of cell form which are both more elaborate and more varied than any other cell type. Neurons typically elaborate two very different types of processes (axons and dendrites) which can be distinguished on the basis of their structural properties, their complement of organelles, and their function (Peters et

\footnotetext{
${ }^{1}$ This work was supported by National Institutes of Health Grant NS12333 to O. S. A. C. was supported by Fogarty International Fellowship F 5TW 02910A. L. B. is a Fellow of the Leukemia Society of America. O. S. is the recipient of Research Career Development Award NS00325. M. R. P. was supported by the Muscular Dystrophy Association during a portion of this research. Special thanks to Lee Snavely for his excellent technical assistance and to Mary Patton Janssen for her secretarial help. The hybridoma antibodies were prepared and analyzed by M. R. P. and L. B. while M. R. P. was in the laboratory of Dr. Iwin Konigsberg, University of Virginia. We would like to thank
}

al., 1976). Of these two types of processes, axons are in many ways the simpler in terms of form, and they are more uniform in structure between cell types and within single cells. While axons may project over great distances, they are rather uniform in diameter throughout their length, exhibiting structural specializations only at nodes of Ranvier and at sites of contact with other cells (terminals or synapses en passant). Dendrites, on the

Dr. Konigsberg for his hospitality and acknowledge support from National Institutes of Health and Muscular Dystrophy Association grants to him.

${ }^{2}$ Present address: Instituto de Investigacion Medica, Mercedes y Martin Ferreyra, Casilla de Correo 389, 5000 Cordoba, Argentina.

${ }^{3}$ Present address: Department of Anatomy, New York Medical College, Valhalla, NY 10595.

${ }^{4}$ To whom reprint requests and other correspondence should be addressed, at Department of Neurosurgery, Box 420 , University of Virginia School of Medicine, Charlottesville, VA 22908. 
other hand, are less uniform in structure both within and between cells. They differ considerably in structure throughout their length and bear microspecializations for the receipt of different types of synapses (spine and shaft synapses). Often the structural specializations for the receipt of synapses are different depending on their position on the dendrite. Dendrites also have a richer complement of organelles than axons, containing ribosomes and specialized structures associated with the postsynaptic densites (psds) and spines (e.g., the spine apparatus; see Gray, 1959). It is the dendrites more than the axons which contribute to the complexity and variety of neuronal form; the level of dendritic complexity ranges from the elaborate trees of Purkinje cells of the cerebellum to the very simple dendrites of granule cells of the cerebellum and some sensory relay neurons (i.e., cells of the ventral cochlear nucleus). The complexity of dendritic form and the richer complement of organelles suggest that the mechanisms of transport into dendrites must be considerably different than into axons.

What role dendritic form plays in neuronal function is currently unclear; certainly the form of dendrites determines the opportunities for connectivity and the electrophysiological properties of synapses made at different dendritic sites (Rall and Rinzel, 1973). Thus, the understanding of how a neuron constructs and maintains its specialized form may contribute to an understanding of how connectivity is regulated and how the functional properties of connections are controlled. There are two primary questions which arise regarding the specification of form: (1) At the cellular level, what distinguishes axons from dendrites? (2) Which of the differences accounts for the unique structural and functional properties of these two types of process? In recent years, it has become increasingly clear that cell form in neurons, as in other cells, is determined to a large extent by the neuronal cytoskeleton (Solomon, 1981). Given the importance of neuronal form and the important role that the neuronal cytoskeleton presumably plays in regulating cell form, one way of approaching the question of how axons differ from dendrites is to ask whether there are differences between the cytoskeleton of axons and dendrites. In this regard, recent observations of microtubules assume special importance.

Microtubules are conspicuous components of the neuronal cytoskeleton and seem to play a crucial role in a wide variety of cellular events, including axonal and dendritic transport (Kreutzberg, 1981; Lasek, 1981), neuronal growth and differentiation (Solomon and Magendantz, 1981), and the regulation of form (Solomon, 1981). While all microtubules seem to contain $\alpha$-and $\beta$-tubulin (the main components of the tubule wall), there appears to be a considerable microheterogeneity and compartmentalization of microtubules in neurons. It has been proposed that different classes of microtubules appear to contain different isotypes of the tubulin subunits, and these different classes of microtubules are compartmentalized within neurons (Gozes and Sweadner, 1981; Gozes and Barnstable, 1982). Of particular interest are the socalled microtubule-associated proteins (MAPs), particularly the high molecular weight MAPs (HMW-MAPs). Immunocytochemical studies using either animal anti- sera against HMW-MAPs (Matus et al., 1981) or a monoclonal antibody against one of the two principle HMW-MAPs, MAP2 (Izant and McIntosh, 1980) have shown that within the CNS, HMW-MAPs are localized exclusively in neurons. Furthermore, Matus et al. (1981) have provided evidence for a striking preferential localization of HMW-MAPs in dendrites, with axons exhibiting no detectable immunostaining. The HMW-MAPs have been implicated in the regulation of the polymerization of tubulin into microtubules (Weingarten et al., 1975) and in the interaction between microtubules and other components of the cytoskeleton (for a discussion, see Vallee et al., 1981). Thus, the differential localization of HMW-MAPs on dendritic microtubules may suggest different functional properties of microtubules in dendrites and axons.

These studies suggest a specific association of HMWMAPs with neurons, but the preferential association with dendritic microtubules, as well as the type of HMWMAPs (MAP1 or MAP'2) associated with them, is still at issue. For example, while Matus et al. (1981) showed a differential staining pattern between tubulin and the HMW-MAPs in Purkinje cells of the cerebellum and pyramidal neurons of the hippocampus, Izant and McIntosh (1980) showed an identical pattern for MAP2 and tubulin in cultured neurons from mouse brain. While neurons in culture may not differentiate neuritic processes in terms of the distribution of the HMW-MAPs, the preferential localization in dendrites is open to some question on other grounds since the antisera utilized by Matus et al. (1981) have not been characterized in terms of which HMW-MAP is being recognized (MAP1 or MAP2). Furthermore, the generality of the preferential localization is unknown, since an extensive examination of brain areas at both the light and electron microsopic level has not yet been undertaken. For these reasons, a clear picture of (1) the distribution of MAPs in axons and dendrites, (2) their degree of association with microtubules, and (3) the type of protein inovlved (MAP1 or MAP2) is highly desirable.

With the above considerations in mind we have studied the distribution and subcellular localization of MAP2 in adult mammalian brain using three hybridoma antibodies against this molecule. For comparison, we also analyzed the distribution of tubulin with a polyclonal animal antiserum against both the $\alpha$ and $\beta$ forms and with three different hybridoma antibodies against $\beta$-tubulin. All proteins were visualized using the three layered method of Sternberger (1979). The principal observations were made in the cerebellum and hippocampal formation, which provide special advantages because of their highly laminated organization. Other regions of the brain (e.g., cerebral cortex, caudate nucleus) were also evaluated in order to compare the localization across cell types and brain regions.

\section{Materials and Methods}

Production of monoclonal hybridoma antibodies against MAP2 and $\beta$-tubulin. Twice-cycled Chinese hamster brain microtubule protein was heat denatured in the presence of $0.05 \%$ SDS, mixed with Freund's complete 
adjuvant, and injected subcutaneously into female $\mathrm{BALB} / \mathrm{c}$ mice. One week later, a second injection of the same immunogen in incomplete Freund's adjuvant was administered. The mice were then rested for 4 months, after which time they were again injected with antigen in incomplete Freund's adjuvant. Five days after this final injection, the mice were sacrificed, their spleens removed, and a preparation of lymphocytes obtained. The lymphocytes were then fused with SP2/0 myeloma cells by the method of Kohler and Milstein (1976) as modified by Oi and Herzenberg (1980). Following plating in 96-well plates and hypoxanthine aminopterin thymidine killing (Shulman et al., 1978), positive clones were determined by duplicate enzyme-linked immunosorbent assays (ELISA) using purified tubulin or MAP2 in the solid phase (see Payne, 1983). After initial cloning, each hybridoma line was subjected to four subclonings prior to the production of antibody in tissue culture medium. Spent culture medium was precipitated with $50 \%$ ammonium sulfate, and the resultant pellets were resuspended in and dialyzed against phosphate-buffered saline (PBS). The hybridoma antibodies against $\beta$-tubulin were additionally purified by protein A-Sepharose affinity chromatography. The antibodies were finally aliquoted and stored at $-80^{\circ} \mathrm{C}$ prior to use. Cross-reactivity to other proteins was examined by reacting the antibodies with electrophoretic blots of microtuble preparations or whole brain homogenates (see below and Binder et al., 1982).

Determination of antibody concentrations. Immulon I plates (Dynatech Laboratories, Alexandria, VA) were coated with $1 \mu \mathrm{g} /$ well of goat anti-mouse IgG (Tago Inc., Burlingame, CA). The plates were washed and blocked with a solution containing PBS, $0.01 \%$ thimerosal, $0.05 \%$ Tween 20 , and $0.4 \%$ bovine serum albumin (BSA). After blocking, equal volumes of monoclonal antibodies in serial dilution were applied to each well. Also on the same plate, a serial dilution of mouse IgG at a known initial concentration was applied. The plates were next incubated overnight at $4^{\circ} \mathrm{C}$. The following day, each well was washed four times (see above) prior to incubation for $1 \mathrm{hr}$ at $25^{\circ} \mathrm{C}$ in peroxidase-conjugate goat anti-mouse IgG (Tago Inc.). Four additional washes preceded the addition of substrate solution which contained $0.4 \mathrm{mg} /$ $\mathrm{ml}$ of $o$-phenylene diamine, $0.003 \% \mathrm{H}_{2} \mathrm{O}_{2}$ in citratephosphate buffer at $\mathrm{pH}$ 5.0. The color was allowed to develop for $20 \mathrm{~min}$, the reaction was stopped with dilute $\mathrm{H}_{2} \mathrm{SO}_{4}$, and the plates were read at $492 \mathrm{~nm}$ on a Titertek Multiskan ELISA reader. Comparison of the linear regions of the monoclonal antibody dilution series to that of the mouse IgG standard readily allowed the calculation of the antibody concentrations.

Immunoblotting of whole brain and hippocampal extracts. Whole rat brains or hippocampi were immersed in Laemmli reducing solution containing $2 \%$ SDS, $5 \% 2-$ mercaptoethanol, $10 \%$ glycerol in $0.0625 \mathrm{M}$ Tris- $\mathrm{HCl}, \mathrm{pH}$ 6.8 , and placed in a Dounce homogenizer in a boiling water bath. Homogenization was performed continuously during a 4-min period of heat treatment, following which the samples were centrifuged at $100,000 \times \mathrm{g}$ for $60 \mathrm{~min}$ at $25^{\circ} \mathrm{C}$. The supernatant from this centrifugation was used in all subsequent elecrophoretic experiments. SDS- polyacrylamide gel electrophoresis was carried out essentially by the method of Laemmli (1970), utilizing a 4 to $16 \%$ linear polyacrylamide gradient. Following this initial electrophoresis, the polypeptides were transferred to nitrocellulose and either stained with $0.1 \%$ amido black, $45 \%$ methanol, $10 \%$ acetic acid, or blocked in 5\% BSA and incubated in hybridoma antibody overnight at $4^{\circ} \mathrm{C}$ using a slight modification of published procedures (Towbin et al., 1979). Following antibody reaction, the nitrocellulose was washed three times in PBS and placed in a 1:1000 dilution of peroxidase-conjugated goat anti-mouse IgG (Tago Inc.) and agitated for $2 \mathrm{hr}$ at room temperature. The nitrocellulose was then washed three times in PBS and placed in a substrate solution containing $0.0025 \%$ o-dianisidine, $0.01 \% \mathrm{H}_{2} \mathrm{O}_{2}$ in $10 \mathrm{mM}$ Tris- $\mathrm{HCl}$, $\mathrm{pH}$ 7.4. After agitating for 5 to $8 \mathrm{~min}$ at room temperature, the reaction was stopped by immersing the nitrocellulose in deionized water. Immunoblots treated in this manner were dried between filter paper and photographed using a Wratten no. 45 filter.

Tubulin was prepared by the method of Weingarten et al. (1975) and MAP2 by the method of Kim et al. (1979). The preparation and characterization of the rabbit antisera against $\alpha$ - and $\beta$-tubulin used in the present study have been described elsewhere (Bender, 1981; Bender et al., 1982).

Immunocytochemical procedures. Adult albino male rats $(n=20)$ were anesthetized and perfused transcardially with $100 \mathrm{ml}$ of $0.1 \mathrm{M} \mathrm{NaPO}_{4}$ buffer (pH 7.2) followed by $800 \mathrm{ml}$ of a fixative containing $4 \%$ paraformaldehyde $/ 0.5 \%$ glutaraldehyde in $0.1 \mathrm{M} \mathrm{NaPO}$ buffer ( $\mathrm{pH}$ 7.2). The brains were left in situ for $1 \mathrm{hr}$ and were then removed and stored overnight in a fresh fixative without glutaraldehyde. The brains were sectioned coronally on a Vibratome ( 40 or $100 \mu \mathrm{m}$ ), collected in PBS (pH 7.2), and stained according to the three-layered method of Sternberger (1979). Individual free-floating sections were preincubated for $1 \frac{1 / 2}{\mathrm{hr}}$ in $1 \%$ normal goat serum (sections reacted with the rabbit antisera against tubulin) or $1 \%$ normal rabbit serum (sections reacted with the monoclonal antibodies) diluted in PBS.

The rabbit anti-bovine brain tubulin $(0.3 \mathrm{mg} / \mathrm{ml})$ was diluted $1: 100$ or $1: 300$ for use. The three anti-brain $\beta$ tubulin antibodies (Tu3B, $0.37 \mathrm{mg} / \mathrm{ml}$; Tu9B, $0.39 \mathrm{mg} /$ $\mathrm{ml}$; Tu12, $0.40 \mathrm{mg} / \mathrm{ml}$ ) were diluted $1: 80,1: 100,1: 300$ or more, whereas the anti-brain MAP2 antibodies (AP9, $0.37 \mathrm{mg} / \mathrm{ml}$; AP13, $0.39 \mathrm{mg} / \mathrm{ml}$ ) were diluted $1: 40,1: 80$, $1: 100,1: 200$, or $1: 300$. After a $24-\mathrm{hr}$ incubation period in the primary antibody, the sections were washed in PBS for $3 \mathrm{hr}$ and then incubated for $3 \mathrm{hr}$ with the secondary antibody. The linker antibody, goat anti-rabbit IgG or rabbit anti-mouse IgG $(0.85 \mathrm{mg} / \mathrm{ml}$; Sternberger Products) was diluted 1:40 in PBS containing 1\% normal serum. After the incubation period, the sections were washed again in PBS and incubated in rabbit or mouse peroxidase-antiperoxidase (Sternberger Products) used at a dilution of 1:80 for light microscopy or 1:40 for electron microscopy. The sections were washed in PBS for $1 \frac{1 / 2}{\mathrm{hr}}$ and incubated for $10 \mathrm{~min}$ in $3^{\prime} 3$-diaminobenzidine (Bionetics Products; $0.5 \mathrm{mg} / \mathrm{ml}$ ) and hydrogen peroxide at a final concentration of $0.02 \%$. The sections were washed in PBS for $1 \frac{1 / 2}{h r}$, and sections for light 
microscopy were mounted on glass slides, air dried, cleared in xylene, and coverslipped with Permount.

Preparation of tissue for electron microscopy. Fortymicrometer stained sections of the hippocampus, cerebellum, and cerebral cortex were trimmed under a dissecting microscope, osmicated, dehydrated, and flat embedded in Epon-Araldite according to standard procedures. Ultrathin sections parallel to the block face were cut on a Porter Blum ultramicrotome and were examined in a Hitachi HU12A electron microscope without prior staining with uranyl acetate or lead citrate. Controls for all of the immunocytochemical procedures involved absorption of the antibodies with a molor excess of the specific antigen or incubation with nonimmune serum.

\section{Results}

The principal observations of this study involve neurons in the hippocampal formation and cerebellum. The principal cell types in both areas have useful characteristics for studies of the localization of cytoskeletal proteins. The pyramidal neurons of the hippocampus proper have dendrites emerging from both the apical and basal pole of the cell, with the axon emerging from the basal pole as well. The granule cells of the dentate gyrus have dendrites which emerge from one pole of the cell only, while the axon emerges from the opposite pole. The axons of both types of cells collect in defined fiber tracts, the alveus and the fimbria in the case of the pyramidal neurons, and the mossy fibers in the case of the granule cells. A similar situation exists in the cerebellum. Pur- kinje cells are collected in a laminated fashion with their prominent dendrites in one lamina, cell bodies in another, and axonal projections emerging from the pole of the cell opposite to the massive dendritic tree. Because of the highly laminated organization of these two brain regions, it is possible to define quite precisely whether the major structural specializations of neurons are differentially labeled by immunocytochemical methods. Hypotheses formed on the basis of light microscopic surveys can then be further explored at the ultrastructural level.

Characterization of the hybridoma antibodies. The specificity of each of the hybridoma antibodies used in this study was characterized by staining nitrocellulose immunoblots of whole brain extracts, hippocampus, or purified bovine brain MAP2 with the different antibodies. As shown in Figure 1, the hybridoma antibodies against MAP2, including one (AP7) which is not used in the present study for immunocytochemistry, stained only MAP2 in homogenates of hippocampus (Fig. 1, lanes $C$ to $E$ ). Since MAP2 migrates as a doublet on SDS gels (Kim et al., 1979; Binder et al., 1982), it is noteworthy that all three hybridoma antibodies reacted with both bands. None of the antibodies stained the region of the gel which contains MAP1. Figures 2 and 3 illustrate the pattern of staining of immunoblots of SDS gels of twicecycled microtubule preparations (Fig. 2) and whole brain extracts (Fig. 3) tested against the three monoclonal antibodies specific for $\beta$-tubulin (Tu3B, Tu9B, and Tu12). All antibodies stained a single band corresponding to the position of $\beta$-tubulin in both the twice-cycled

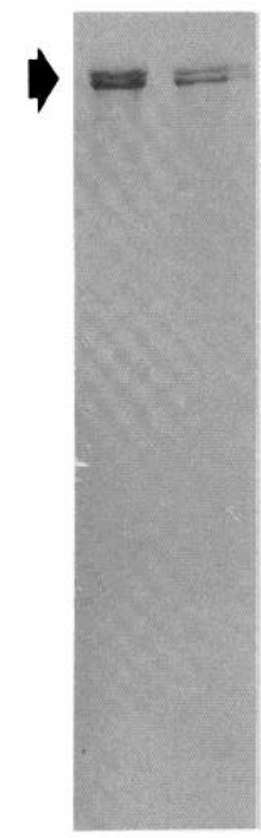

A
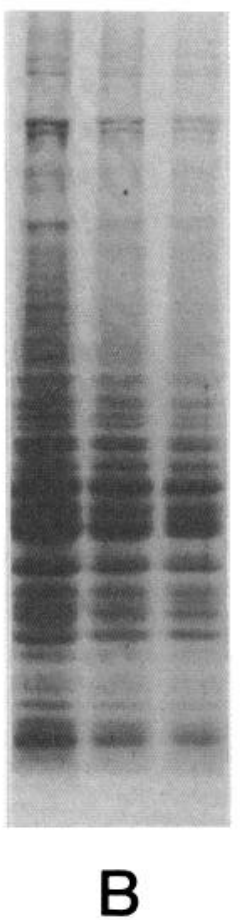

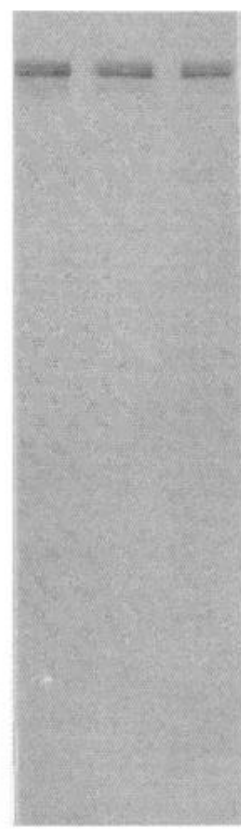

C
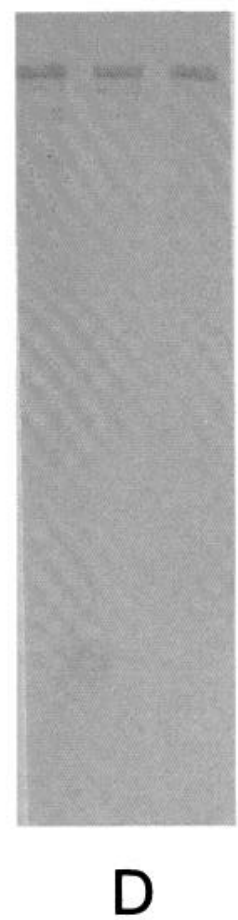
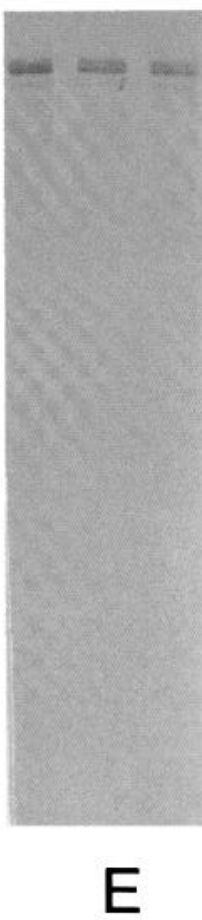

Figure 1. Nitrocellulose blot of an SDS-extract of rat cerebral cortex and purified MAP2 (arrow). Lane A, Two loadings of purified bovine brain MAP2 stained with amido black. Lane $B$, Three loadings of cerebral cortex stained with amido black. Lanes $C$ to $E$, Blots of cerebral cortex loaded similar to the ones seen in lane $B$ but immunostained with AP7, AP9, and AP13, respectively. AP7 was not used for the immunocytochemical studies of this report. 
microtubule preparation (Fig. 2) and whole brain homogenates (Fig. 3). The hybridoma antibodies employed in these studies were all of the $\mathrm{IgG}_{1}$ subclass.

Light microscopic observations. Sections of rat hippocampal formation or cerebellum reacted with polyclonal antisera against tubulin or with the antitubulin hybridoma antibodies revealed a wide variety of stained cellular compartments. The reaction product was concentrated in dendrites of both pyramidal (Fig. $4 A$ ) and granule cells as well as in Purkinje cells of the cerebellum. Dendrites could be easily distinguished because of their orientation and their emergence from the neuronal cell body. Reaction product was also present in the cell cytoplasm, particularly in the cell periphery; nuclei remained virtually unstained. Several axonal tracts were also prominently stained, including the fornix, fimbria, and corpus callosum (Fig. $4 B$ ), as well as the white matter in the cerebellum (Fig. $4 C$ ). Fine networks of stained processes were also observed between the cell layers of the dentate gyrus (in the hilus) and in the molecular layer (neuropil) of the hippocampus proper and cerebellum. These processes were perpendicular to the dendrites and had an orientation identical to the major populations of presynaptic afferents which course through these regions of neuropil en route to their termination sites on dendrites. Immunostaining with any of the monoclonal antibodies against $\beta$-tubulin yielded a pattern which was

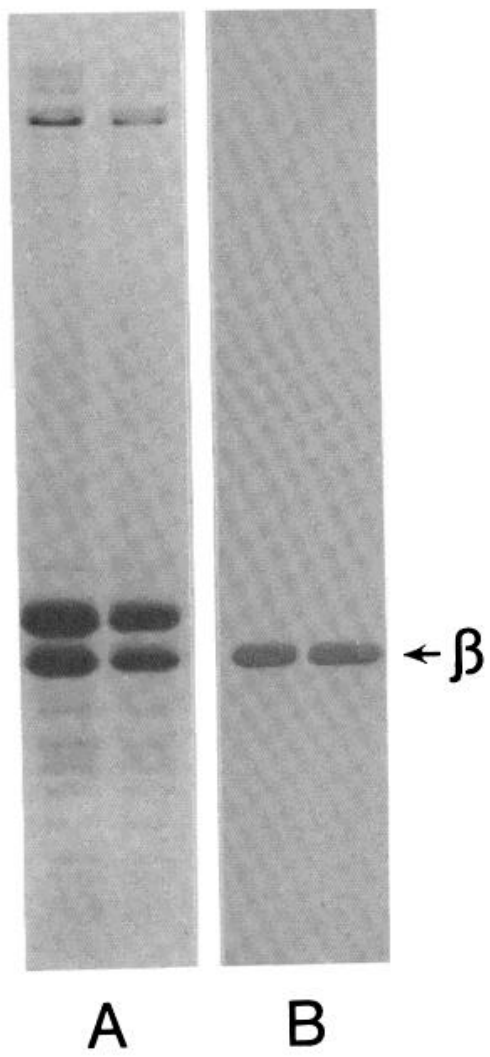

Figure 2. Nitrocellulose blot of twice-cycled rat brain microtubule protein. Lane $A$, stained with amido black. Lane $B$, Immunostained with Tu9B, an anti- $\beta$-tubulin antibody. All of the tubulin monoclonal antibodies used in this report react with only $\beta$-tubulin.

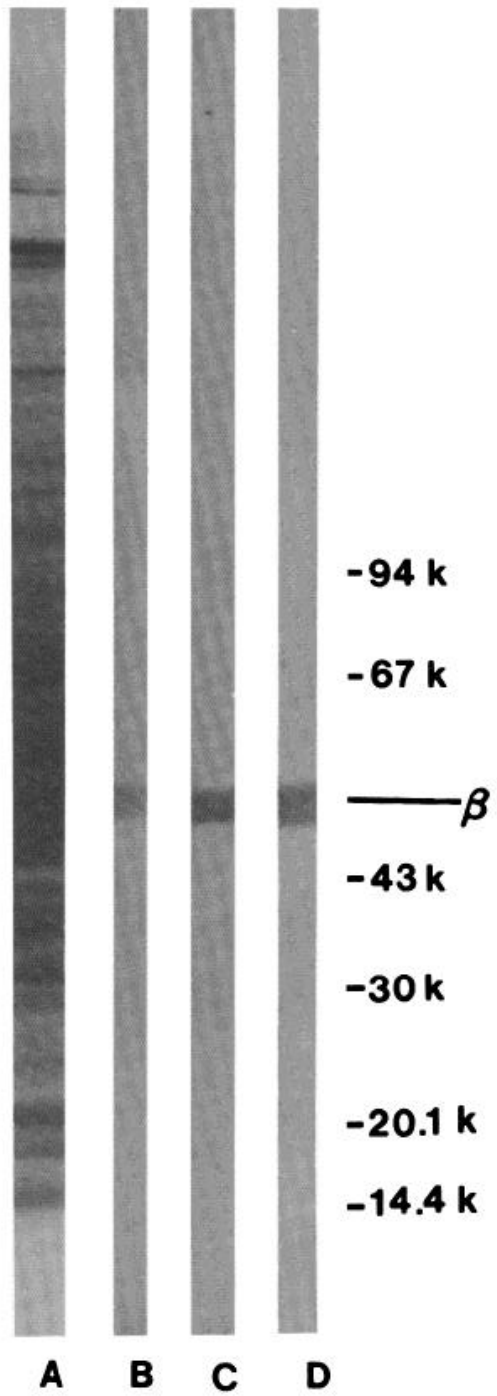

Figure 3. Nitrocellulose immunoblots of whole brain extracts tested against three hybridoma antibodies specific for $\beta$-tubulin. Lane A, amido black stain of the nitrocellulose blots of bovine brain extracts tested against three antibodies specific for $\beta$-tubulin. Lanes $B$ to $D$, Adjacent unstained nitrocellulose strips of brain extracts reacted with Tu3B, Tu9B, and Tu12, respectively, and visualized as indicated under "Materials and Methods." In all three cases only a single band is illuminated corresponding to the position of $\beta$-tubulin. The numbers on the right designate the relative molecular weight of the protein standards electrophoresed on the same slab gel.

indistinguishable from that observed with the polyclonal tubulin antibody (see Figs. $6, B, D$, and $E$, and $7 E$ ).

A considerably different localization was evident in the case of MAP2. The reaction produced appeared to be preferentially localized in the neuronal perikaryon and in dendrites (Figs. 5 and 6). Indeed, stained dendrites stood out prominently against a very clear background, owing to the absence of staining of nondendritic processes (Fig. 6). In addition, the pattern of dendritic staining for MAP2 was different than for tubulin. For example, in the cerebellum, the hybridoma antibodies against MAP2 stained not only the primary and secondary dendrites of Purkinje cells, but also the very fine 

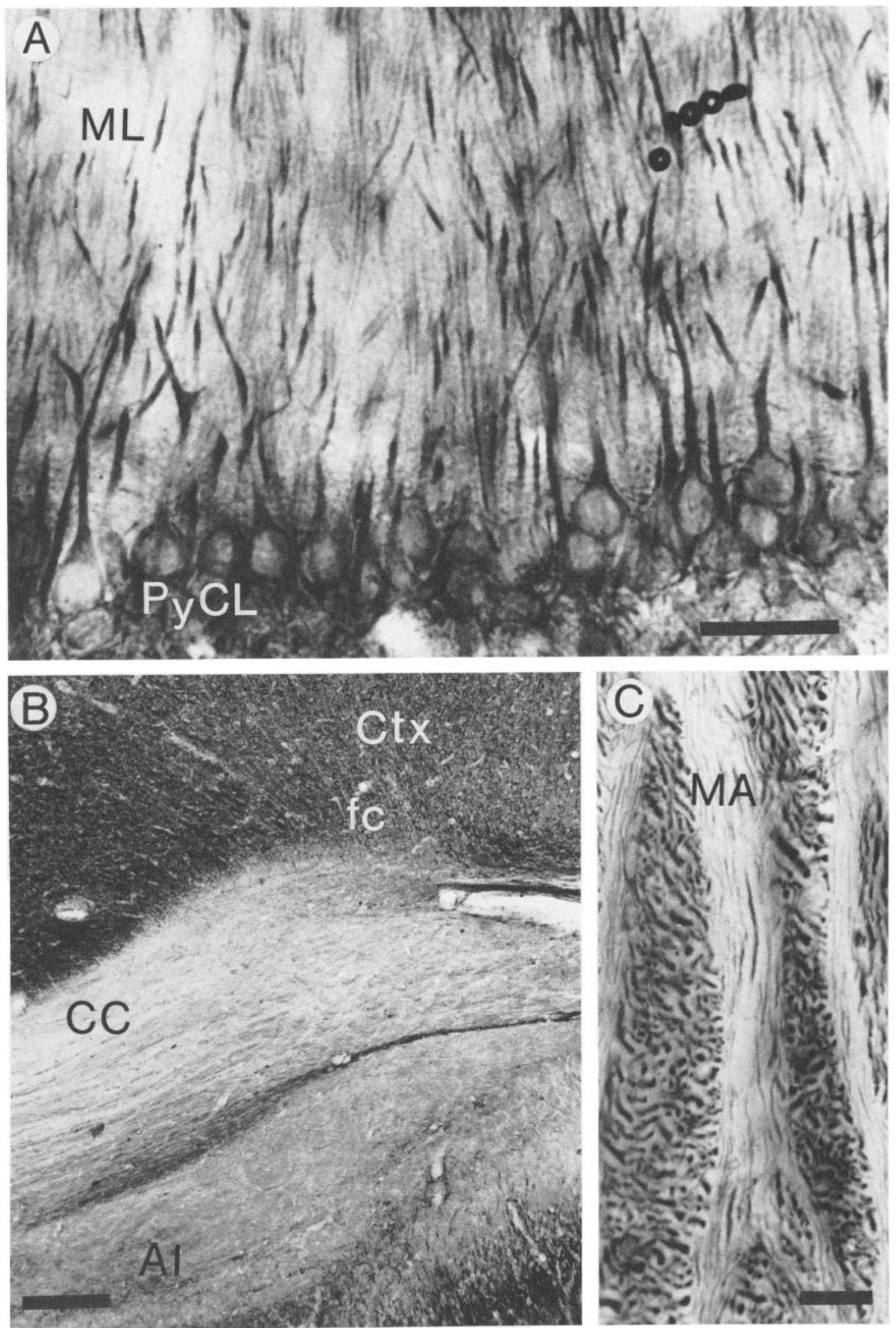

Figure 4. A, Hippocampal pyramidal neurons reacted with a rabbit antiserum against tubulin. The section (100 $\mu \mathrm{m}$ thick) is focused to display the dendritic processes. $M L$, molecular layer; $P y C L$, pyramidal cell layer. $B$, Rat cerebral cortex $(C t x)$ reacted with a monoclonal antibody against $\beta$-tubulin (Tu9B). Note the staining in the white matter. $f c$, fasciculum cingulum; $C C$, corpus callosum; $A l$, alveus. Bar, $100 \mu \mathrm{m}$. C, Myelinated axons (MA) from cerebellar white matter stained with Tu12. Bar, $250 \mu \mathrm{m}$. 

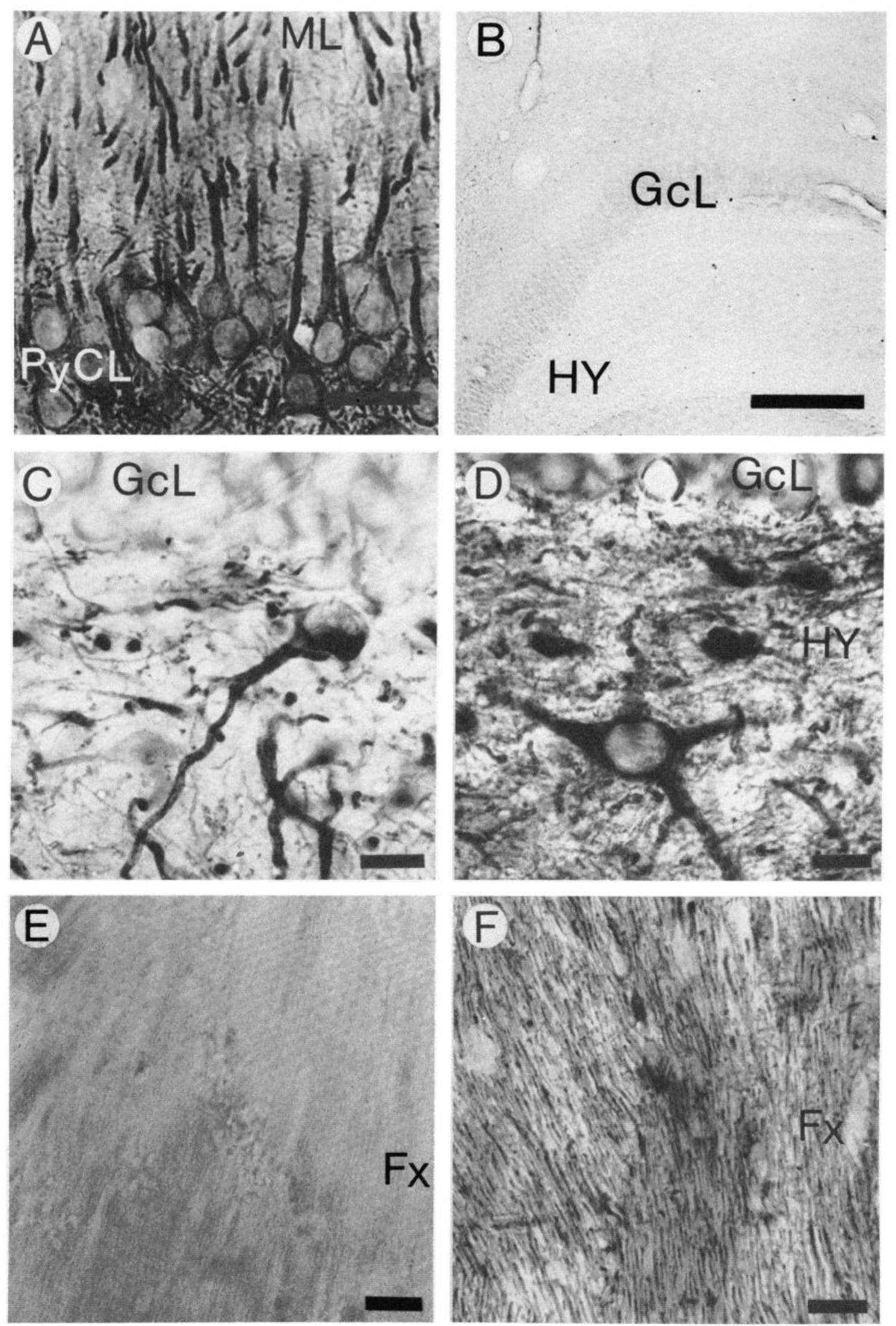

Figure 5. A, Hippocampal pyramidal neurons reacted with a monoclonal antibody specific for MAP2. The section $(40 \mu \mathrm{m})$ is focused to display the dendritic processes. Bar, $50 \mu \mathrm{m}$. Same abbreviations as in Figure $4 A$. B, Section of rat hippocampus reacted with AP9 $(0.37 \mathrm{mg} / \mathrm{ml})$ previously absorbed with a molar excess of purified MAP2. $H Y$, dentate hilus; $G c L$, granule cell layer. $B a r, 50 \mu \mathrm{m} . C$ and $D$, Detail of staining in the dentate hilus from a section reacted with AP9 $(C)$ or AP13 $(D)$. Both antibodies were used at a dilution of 1:40. Note the fine granular staining with AP13. Bar, $25 \mu \mathrm{m}$. $E$ and $F$, MAP2 immunoreactivity in fornix fibers $(F x)$ from sections reacted with AP9 (E) or AP13 $(F)$. Both antibodies were used at a dilution of 1:40. Bar, $25 \mu \mathrm{m}$. 

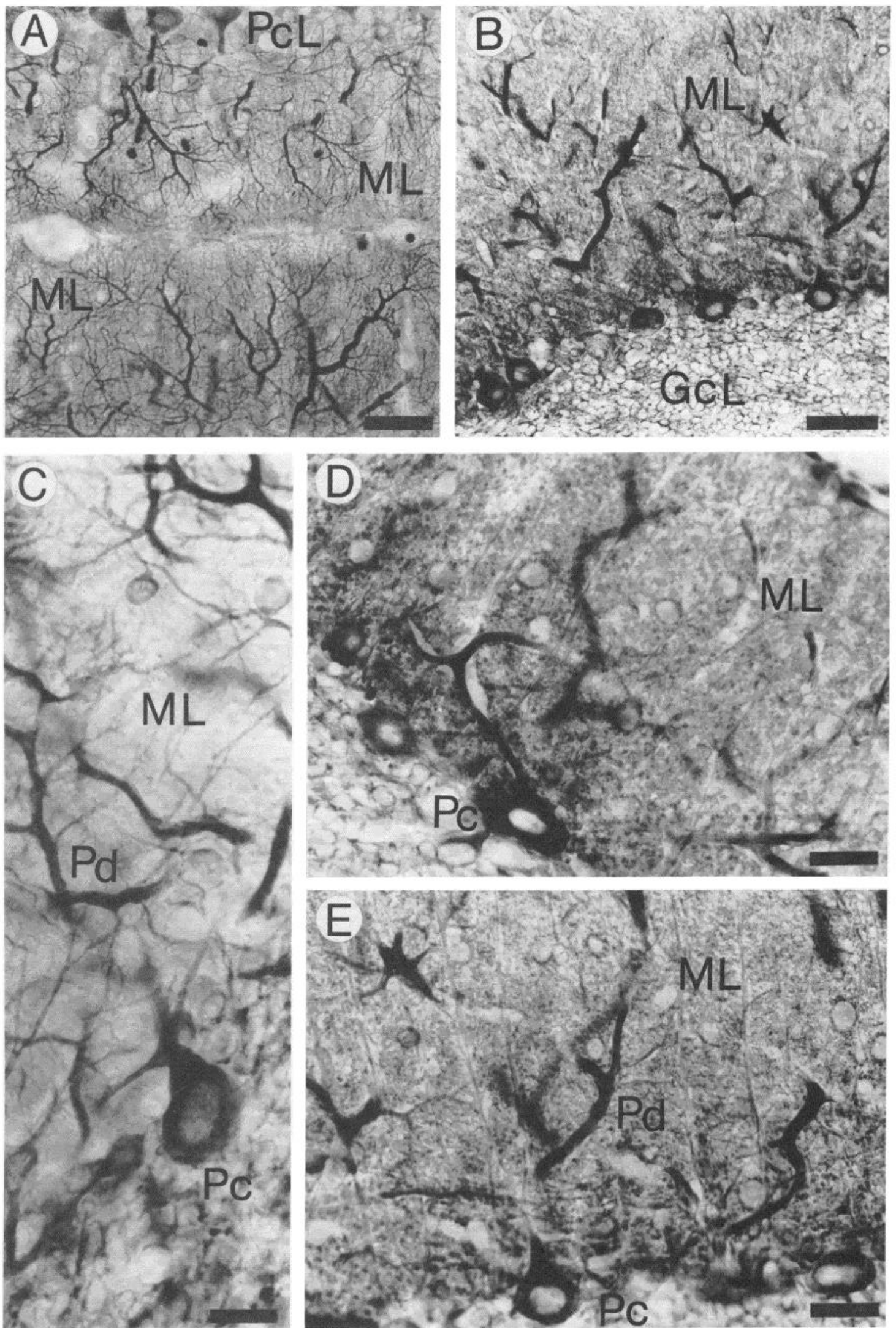

Figure 6. Section of rat cerebellum reacted with AP13 $(A)$ or Tu9B $(B)$. Note the difference in the pattern of staining of dendritic processes with both antibodies. $M L$, molecular layer; $G c L$, granule cell layer. Bar, $200 \mu$ m. $C$, Detail of staining of Purkinje cells $(P c)$ with AP9. Note the staining of the very fine dendritic ramifications and the absence of staining in parallel fibers or Bergman glia. Pd, Purkinje cell dendrite. Bar, $50 \mu \mathrm{m}$. Detail of staining of Purkinje cells reacted with Tu12 $(D)$ or Tu9B $(E)$. Note the staining of dendritic processes, as well as parallel fibers and Bergman glia. Bar, $50 \mu \mathrm{m}$. 
ramifications (Fig. 6, $A$ and $C$ ). This pattern of staining was not seen with anti-tubulin at any of the dilutions used in this study (Fig. 6, $B, D$, and $E$ ).

The most significant difference between tubulin and MAP2 was in the staining of axons. Of the two hybridoma antibodies against MAP2, AP9 yielded essentially no axonal staining. For example, no immunoreactivity was ever observed in the fiber tracts that course through the cerebellum (Fig. 7), in the fine parallel fibers in the neuropil regions of the cerebellum (Fig. $6, A$ and $C$ ) and hippocampus, or in the corpus callosum (Fig. 7), caudate nucleus, lateral olfactory tract, or medial forebrain bundle. This lack of axonal staining with AP9 was observed even when the antibodies were used at high concentrations (dilutions less than 1:100). However, in the case of AP13, in addition to the strong immunostaining of dendritic processes (Fig. 6A), lightly labeled axons were observed in cerebellar white matter (Fig. $7 C$ ), fornix, dentate hilus (Fig. 5, $D$ and $F$ ), and cingulate cortex. Axonal staining with AP13 was not observed in the corpus callosum (Fig. 7A), in fiber tracts in the caudate nucleus, or in parallel fibers coursing through the molecular layer of dentate gyrus, hippocampus, or cerebellum. The axonal staining and the more prominent dendritic staining were eliminated following immunoabsorption of the antibody with a molar excess of purified brain MAP2 (see Fig. $5 B$ ).

Electron microscopic observations. Localization of the reaction product from the immunocytochemical procedures at the electron microscopic level proved to be somewhat problematic owing to the limited penetration of the antibodies into the tissue. The penetration was helped little if at all by the addition of $0.02 \%$ saponin or $0.1 \%$ Triton $\mathrm{X}-100$. Thus, only the outer few microns of tissue were suitable for analysis, and even within this zone some processes were well stained while adjacent ones were not. Nevertheless, when the blocks were sectioned en face rather than end on, acceptable immunocytochemical preparations could be obtained, although not every process of a given type within a single section exhibited equivalent staining. Despite these difficulties, the electron microscopic analysis fully confirmed the light microscopic observations and also provided additional information.

As previously reported (Caceres et al., 1983a; Matus et al., 1981), tubulin immunoreactivity was found in the perikaryon of neurons and glial cells and decorating dendritic and axonal microtubules; the reaction product was also found in postsynaptic densities, both in shaft and spine synapses. Little or no staining was observed in the spine cytoplasm, however (see Fig. 10). The same pattern was obtained with the rabbit antisera or the hybridoma antibodies against $\beta$-tubulin. Reaction product was also found in presynaptic terminals.

In the case of MAP2, reaction product was found in the cell perikaryon (Fig. 8), where it was mainly associated with the outer surface of mitochondria and the plasma membrane. The distribution of the reaction product in the cell perikaryon was nonpolarized, in the sense that both the apical (dendritic) and basal (axonal) poles appeared equally stained (Fig. 8). In the neuropil, reaction product was found to decorate dendritic but not axonal microtubules. The psds were heavily stained (Fig. 9). In addition, the antibodies to MAP2 heavily stained the cytoplasm of dendritic spines, both in the neck and spine head (Figs. 10 and 11). This pattern of staining was in marked contrast to that observed with tubulin, where there was heavy staining of the dendrite proper and the psd but essentially no staining of the spine cytoplasm (Fig. 9D). This absence of staining of the spine cytoplasm was observed with all of the hybridoma antibodies against $\beta$-tubulin and the polyclonal antisera. The general appearance of the MAP2 reaction product in the spine cytoplasm was amorphous or flocculent (Fig. 11). The pattern of staining with AP13 confirmed the light microscopic observation of reaction product in some axons (data not shown). The intensity of the reaction product was considerably lower than that observed in dendritic microtubules or in axons stained with antitubulin. Immunoabsorption of the primary antibodies with a molar excess of the antigens or incubation with nonimmune serum resulted in no staining.

In our material, no staining for MAP2 was ever observed in glial cells or their processes, in ependymal cells, or in Schwann cells. Glial staining was also not observed in situations in which glial proliferation and hypertrophy are induced as a consequence of a lesion which denervates a portion of the neuropil (data not shown).

\section{Discussion}

The present observations confirm and extend the recent studies of Matus et al. (1981) and Izant and McIntosh (1980) on the distribution and subcellular localization of the HMW-MAPs in neurons. Our observations extend those of Matus et al. (1981) since the hybridoma antibodies which we have used are specific for MAP2 and do not cross-react with MAP1. Our results also suggest that, although MAP2 is preferentially localized in dendrites, there appears to be a limited amout of MAP2 in some axons. In addition, our observations provide new evidence about the subcellular localization of MAP2 in dendrites, particularly in dendritic spines and within psds. The localization of MAP2 in spines is of particular interest since microtubules are not typically observed in spines (but see below and Gray et al., 1982), and little tubulin immunoreactivity was detected within the cytoplasm of dendritic spines in the present study. This latter observation suggests a role for MAP2 independent of microtubules. In evaluating these results, it is important to consider the nature of the antibodies and the evidence which immunocytochemical studies provide.

In the case of the hybridoma antibodies, specificity can be inferred from the staining pattern of immunoblots of whole brain or hippocampus; only the specific molecule to which the antibodies are directed showed staining. These data are further supported by the immunoabsorption experiments, the absence of staining when the sections were incubated with normal mouse serum, and the differential staining pattern observed with the different antibodies. The rabbit antiserum against tubulin used in the present study has also been well characterized. This antibody was purified by affinity chromatography, and its specificity has been documented on the basis of im- 

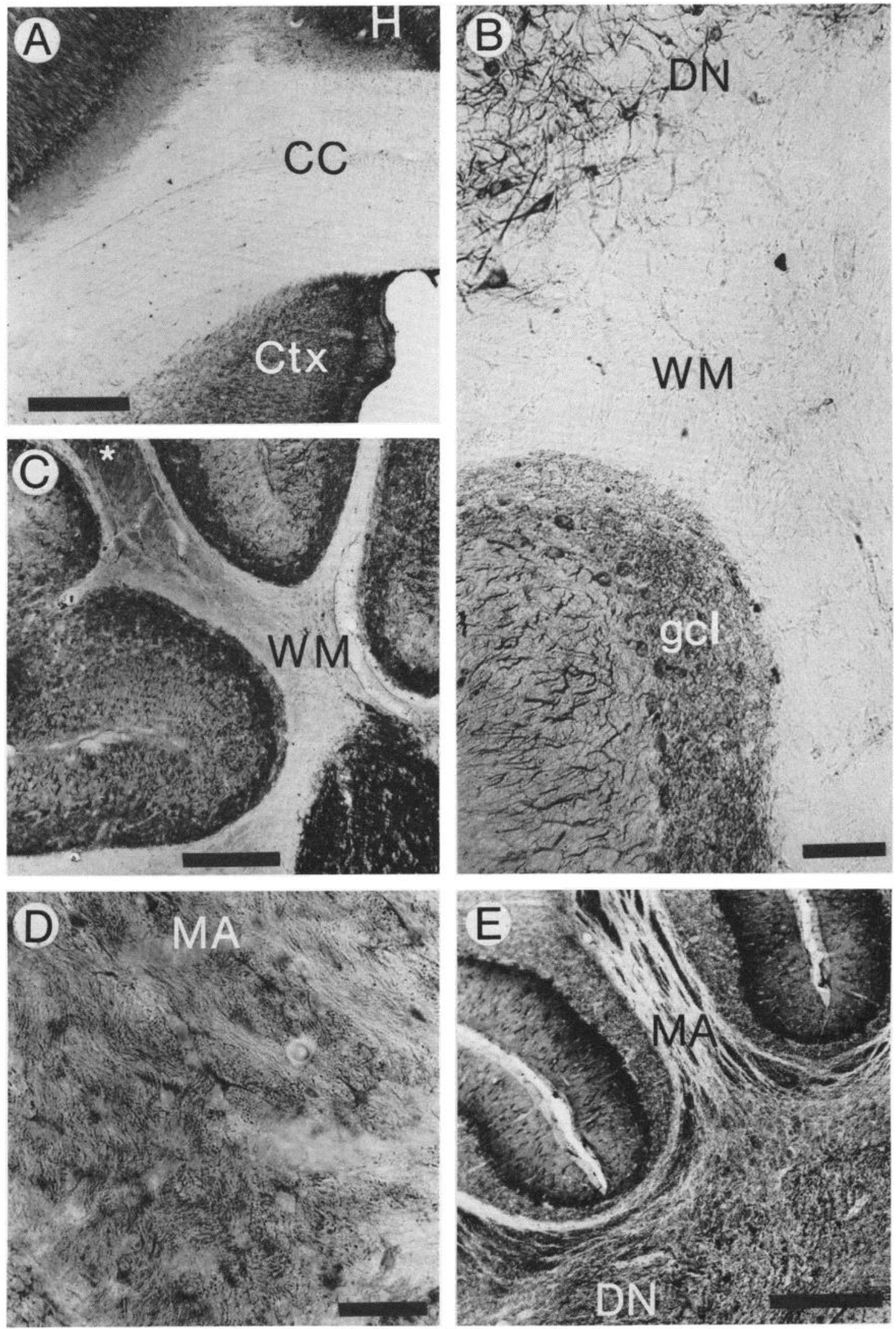

Figure 7. A, Rat cerebral cortex (Ctx) reacted with AP13. Note the complete absence of staining in corpus callosum (CC). $H$, hippocampus. Bar, $100 \mu \mathrm{m}$. B, Rat cerebellum reacted with AP9. Note also the absence of staining in the white matter (WM). $D N$, Cerebellar deep nuclei. Bar, $100 \mu \mathrm{m}$. C, Rat cerebellum reacted with AP13. Note the staining in the white matter. Bar, 100 $\mu \mathrm{m}$. $D$, Detail of staining with AP13 in cerebellar white matter. The photograph was obtained from the area marked with an asterisk in Figure $7 C . M A$, myelinated axons. Bar, $100 \mu \mathrm{m}$. E, Rat cerebellum reacted with Tu12. Bar, $100 \mu \mathrm{m}$. 


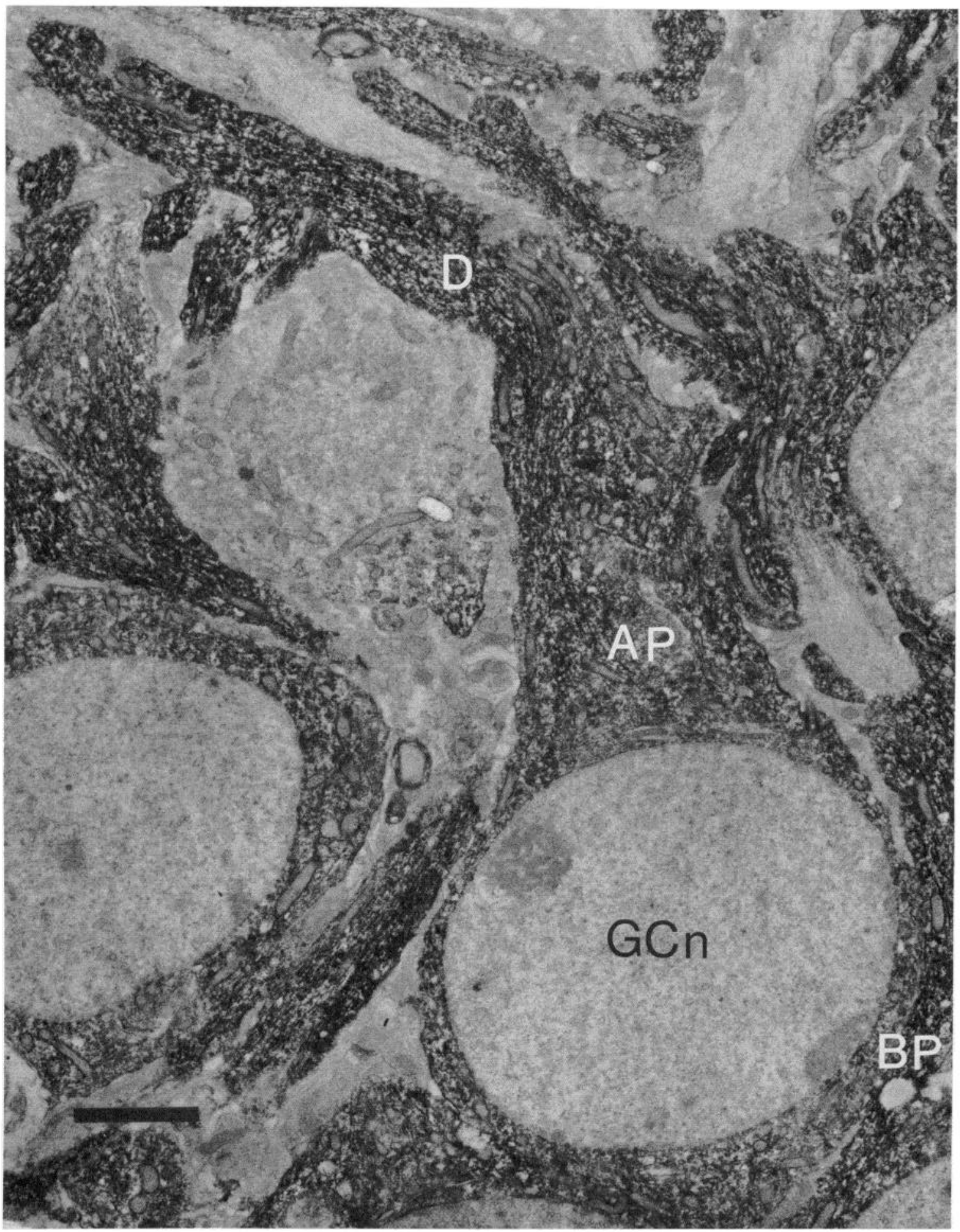

Figure 8. Electron micrograph showing the nonpolarized distribution of MAP2 in dentate granule cells. Note the staining in both the apical $(A P)$ and basal poles $(B P)$ (AP9 diluted 1:100). $G C n$, granule cell nucleus; $D$, dendrite. Magnification $\times 7,500$; bar, $2 \mu \mathrm{m}$.

munodiffusion and hemagglutination (Bender, 1981; Bender et al., 1982).

Our results suppport the notion that MAP2 is widely distributed among neurons, but that it is also relatively specific to them, since no staining was ever observed in glial cells or their processes, in ependymal cells, in en- dothelial cells, or in Schwann cells. These observations are in agreement with the study of Izant and McIntosh (1980), which showed the exclusive localization of MAP2 in neurons from primary cultures of mouse brain and in differentiated neuroblastoma cells, and with the observations of Matus et al. (1981). Our results do not, how- 

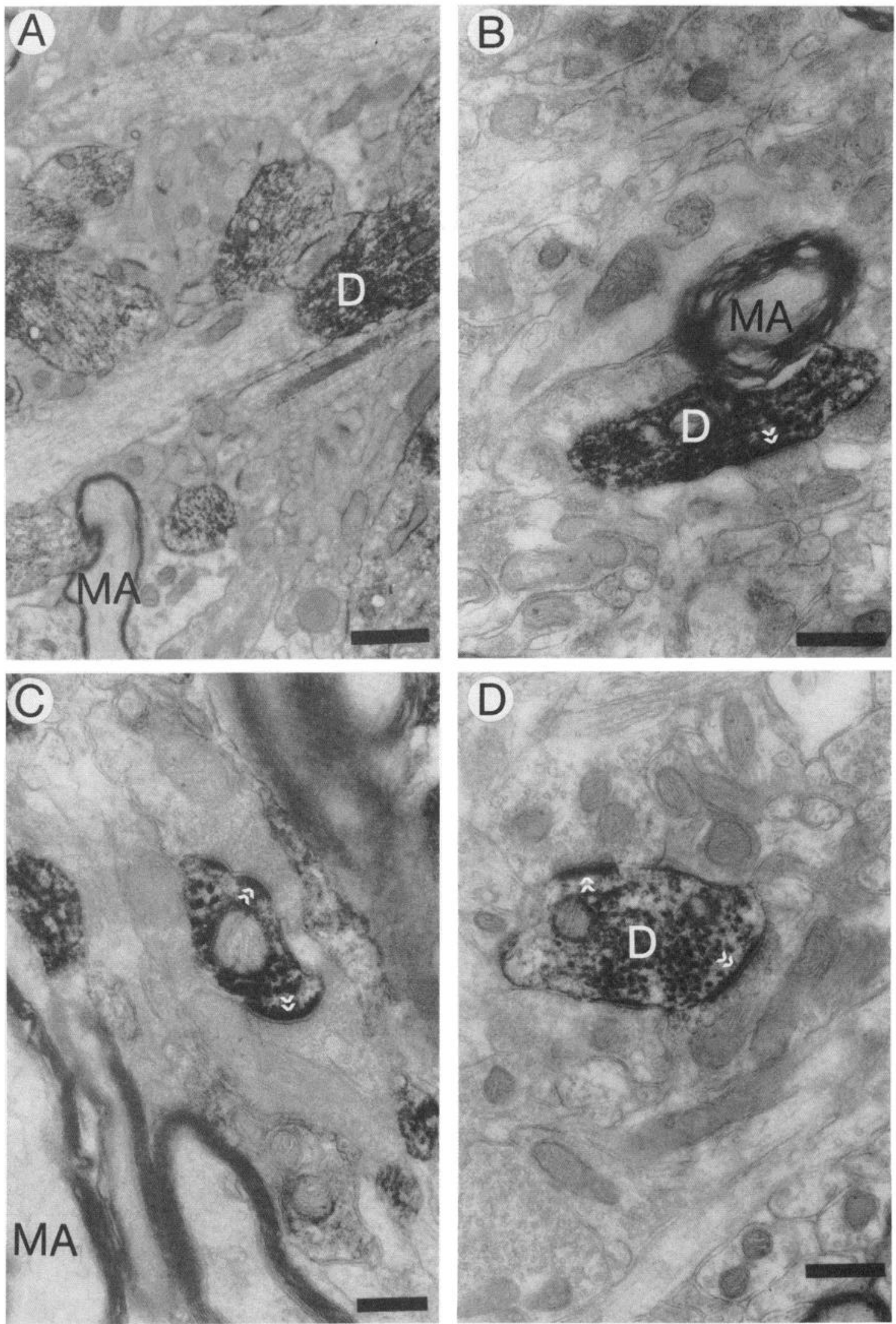

Figure 9. Electron micrographs showing the subcellular distribution of MAP2 in the molecular layer of the dentate gyrus of sections reacted with AP9 $(A$ and $B)$ or AP13 $(C$ and $D)$. The arrowheads indicate stained postsynaptic densities in shaft synapses. $A, \times 26,000 ;$ bar, $0.5 \mu \mathrm{m}$. $B, \times 30,000$; bar, $0.5 \mu \mathrm{m} . C, \times 65,000 ;$ bar, $0.25 \mu \mathrm{m} . D, \times 52,000 ;$ bar, $0.25 \mu \mathrm{m}$. 

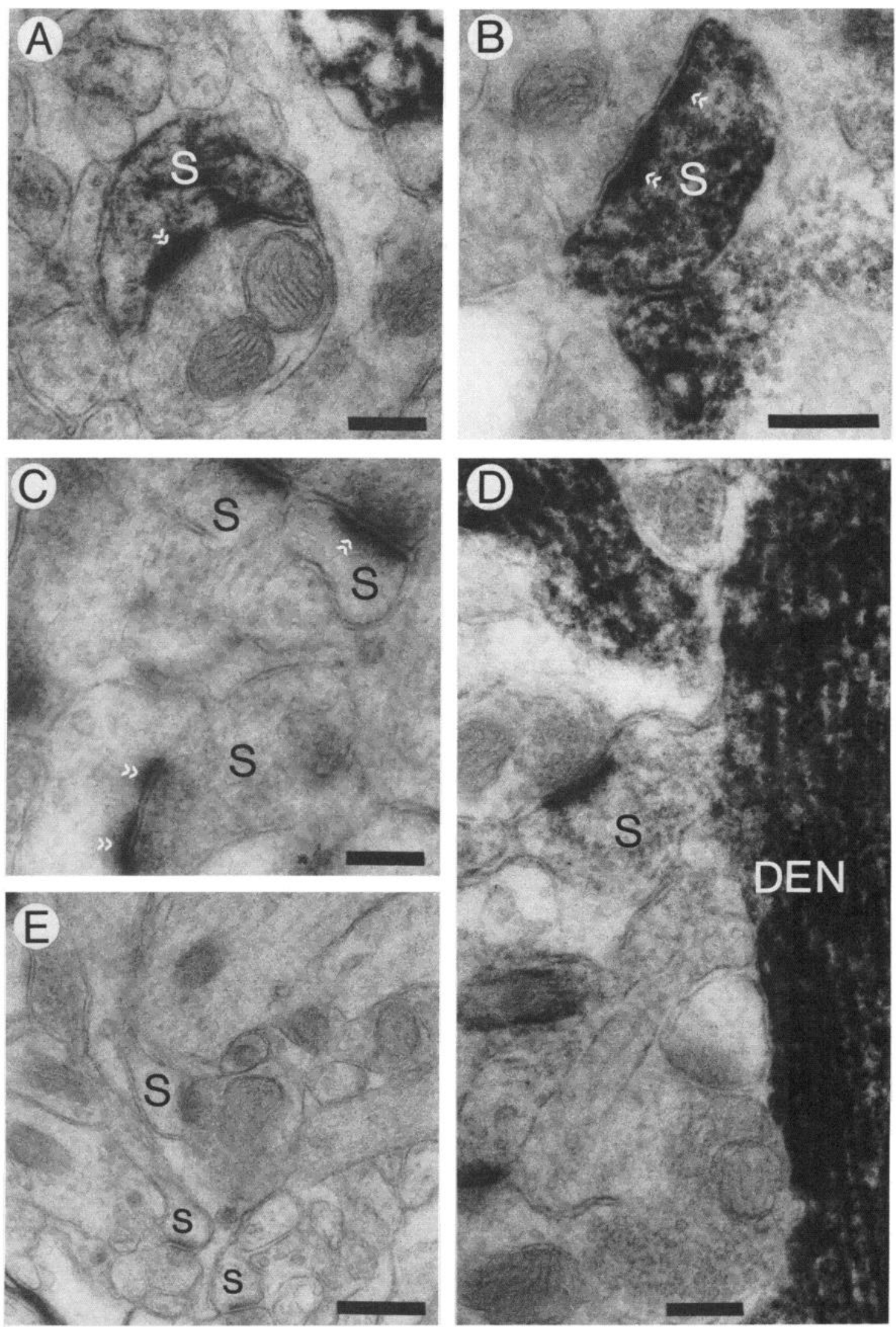

Figure 10. Electron micrographs showing the distribution of MAP2 $(A$ and $B)$ and tubulin $(C$ and $D)$ in dendrites and dendritic spines. $A$ and $B$, Spine heads $(S)$ from a section reacted with AP13. The arrowheads indicate the stained postsynaptic densities. $A, 52,500 ; b a r, 0.25 \mu \mathrm{m} . B, \times 75,000 ;$ bar, $0.25 \mu \mathrm{m}$. $C$, Spine head from a section reacted with Tu9B. Note the absence of staining in the spine cytoplasm. The arrowheads indicate the stained postsynaptic densities. Magnification $\times 52,500 ; b a r, 0.25 \mu \mathrm{m} . D$, Electron micrograph from a section reacted with Tu12. Note the intense staining of dendritic microtubules $(D E N)$ but the absence of staining in the spine head $(S)$. Magnification $\times 52,500 ; b a r, 0.25 \mu \mathrm{m}$. E, Electron micrograph from a section reacted with AP13 previously absorbed with a molar excess of MAP2. Magnification $\times 15,000 ; b a r, 1 \mu \mathrm{m}$. 


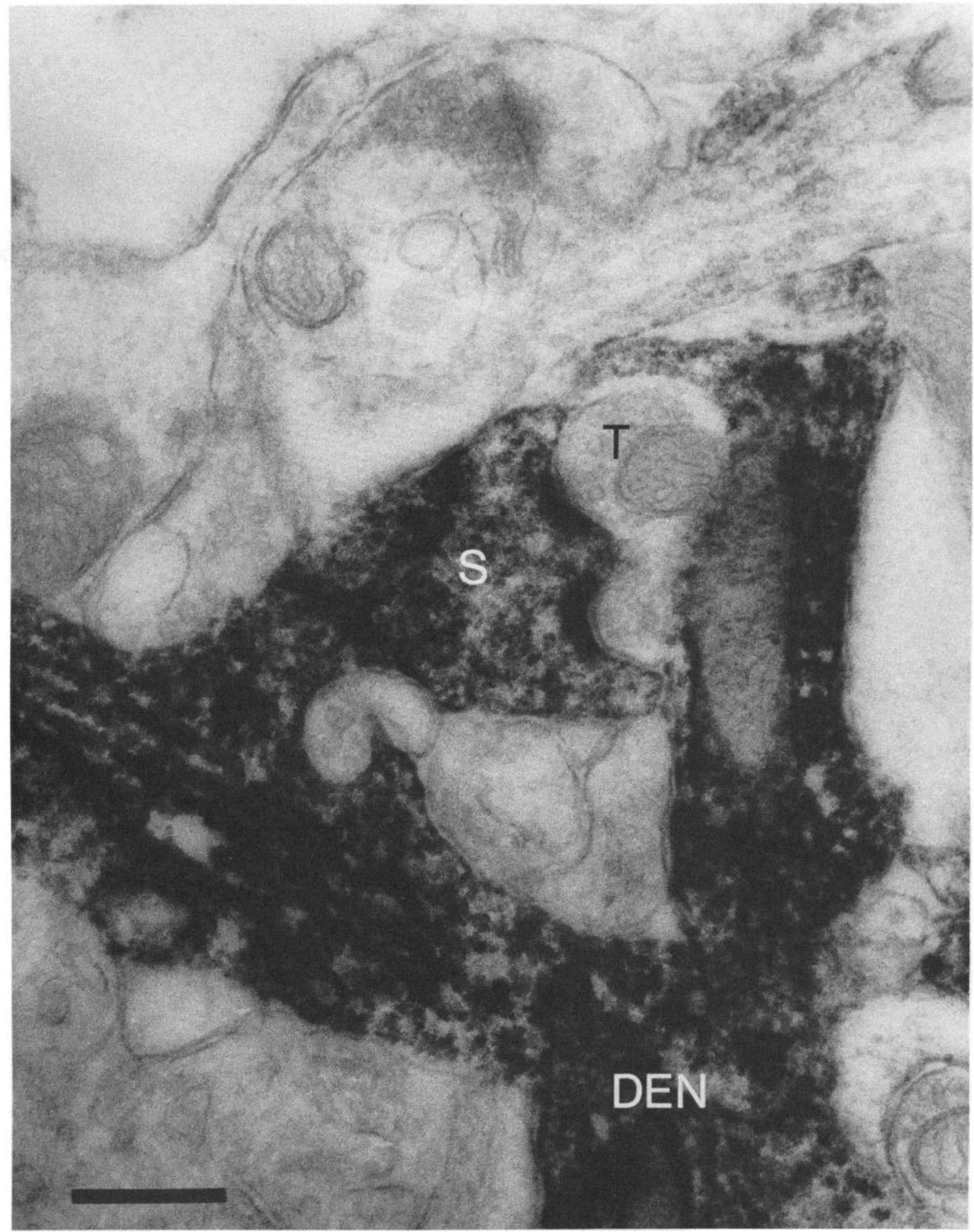

Figure 11. Electron micrograph from a section reacted with AP9. Note the intense staining of the dendritic shaft (DEN), the spine cytoplasm, and the postsynaptic densities. $T$, presynaptic terminal. Magnification $\times 101,500 ; b a r, 0.25 \mu \mathrm{m}$.

ever, provide any evidence about the distribution of this protein in cell types other than those found in brain.

Within neurons, MAP2 appears to be preferentially but not exclusively localized in dendrites. It is not only the absence of MAP2 immunoreactivity in axons that makes the staining in dendrites so striking, but also the pattern observed within the dendrite. Both hybridoma antibodies against MAP2 stained dendrites prominently; and, in cerebellar Purkinje cells, the very fine dendritic ramifications were also obvious with these antibodies. These fine dendrites were not discernible in the preparations stained with tubulin antibodies. It is possible, 
however, that the fine dendritic processes were simply not resolvable against a background of small stained axons in the case of the tubulin immunocytochemistry. Although dendrites were certainly the most heavily stained elements in the CNS with the MAP2 antibodies, the immunostaining of some axons with AP13 suggests the presence of low concentrations of MAP2 in some axons. It is important to emphasize that only a few sets of axons were stained by AP13 and that the observed staining was significantly less intense than that in dendrites or in any axon stained with either the tubulin antiserum or the hybridoma antibodies against $\beta$-tubulin. The differential staining is particularly significant since no axonal staining was observed with AP9 using the same antibody concentration (determined by ELISA). An important implication of these observations is that an absence of staining with particular antibodies does not necessarily indicate an absence of the antigen. We have discussed this problem in interpreting negative evidence in our studies of other molecules (Caceres et al., 1983b). We are left then with the question of why one of the antibodies stains MAP2 in axons while the others do not. One possibility is that in axons, certain epitopes of the MAP2 molecule may be unavailable to interact with the antibody, due to intermolecular interactions of MAP2 with other proteins or to intramolecular interactions caused by post-translational modifications, such as phosphorylation (Sloboda et al., 1975). It is also conceivable that axons which exhibit MAP2 immunoreactivity contain a MAP2 isotype which is different from that in dendrites, lacking the epitope recognized by AP9 but sharing the epitope recognized by AP13. One could argue that these would then be different proteins because of sequence differences. Nevertheless, the molecules recognized by each of the antibodies co-isolate with microtubules and migrate as a doublet at the position of MAP2. Thus, it seems inescapable that certain axons contain a microtubule-associated protein indistinguishable from MAP2, albeit perhaps in small quantities. This result is consistent with a recent biochemical study on the distribution of the HMW-MAPs in brain tissue, in which MAP2 was identified in low concentrations in white matter (Vallee, 1982).

Our observations also provided evidence about the subcellular localization of MAP2 in dendrites. Previous biochemical and immunocytochemical studies have shown that the HMW-MAPs are a component of postsynaptic densities (Cotman and Kelly, 1980; Matus et al., 1981). Our results fully confirm this previous research. Within dendrites, the reaction product seems to be preferentially associated with microtubules, and this too is certainly not surprising given the fact that the MAPs co-purity with microtubules. It is interesting, however, that reaction product also appears in regions of the dendritic cytoplasm where there are no noticeable microtubules. In evaluating the staining of organelles such as microtubules it is, of course, important to consider the possibilities of precipitation of the antigen onto intracellular structures or a nonuniform loss of antigen from lightly stained areas (for a further discussion of these issues, see Caceres et al., 1983b). Given the high degree of correspondence between the conclusions drawn from biochemical studies and the conclusions from the present immunocytochemical observations, however, we feel reasonably comfortable that the distribution revealed by immunocytochemistry is accurate.

One aspect of the present data which is of special interest is that MAP2 is present not only in association with microtubules, but also within the cytoplasm of dendritic spines and within the psd (see also Caceres et al., 1983a). The monoclonal antibodies against MAP2 strongly stained the cytoplasmic compartment of the spine neck and head, where there was also little or no staining with the antibodies directed against tubulin. These results are of particular interest, since microtubules are rarely observed in well-developed spines in material prepared conventionally for electron microscopy (see Peters et al., 1976). The high concentrations of MAP2 in the absence of detectable microtubules or tubulin would suggest an important role for MAP2 independent of microtubules. It is important to note, however, that conventional preparative procedures may be inadequate to preserve some types of microtubules. For example, Gray et al. (1982) have detected several types of microtubules which can be observed only in material prepared for electron microscopy following pretreatment with high concentrations of albumin. With this special pretreatment, microtubules may also be observed within spines, particularly within developing spines in young animals (Westrum et al., 1980). There is still some controversy, however, about whether these represent classes of microtubules which are unusually sensitive to preparative procedures or whether the pretreatments may artifactually polymerize microtubules which are not present in situ (Gray et al., 1982). Nevertheless, even if these special microtubules do not exist in vivo, the fact that they can be produced by pretreatment suggests that the components of microtubules are available and could conceivably be used by the neuron to construct microtubules in special circumstances.

Whatever the status of microtubules in mature spines in vivo, it is clear that there are high concentrations of MAP2 in sites with few if any microtubules and low concentrations of tubulin. It seems likely that any microtubules which did exist in such an environment would have different properties than microtubules at other sites with higher tubulin concentrations. The question then becomes, what is the significance of the high concentrations of MAP2 in the cytoplasm of the spine and within the psd? Recent evidence from our laboratory and others has also shown strong actin immunoreactivity in the dendritic spine (Caceres et al., 1982b, 1983a). The colocalization of actin and MAP2 within the cytoplasm of the dendritic spine raises the interesting possibility that MAP2 in brain is not only acting as a microtubuleassociated protein. In this context, MAP2 may well play a role in regulating gel-sol transitions of actin and other cytoskeletal proteins (see Griffith and Pollard, 1982; and Caceres et al., 1983a, for further discussion).

The present results, in conjuction with the observations of others, clearly suggests that the cytoskeleton of dendrites differs considerably from that of axons, particularly in the types of microtubules. These results may have important implications for understanding how the 
neuron is able to transport different material into dendrites and axons. As noted in the introduction, the composition of axons and denderites differs considerably in terms of the organelles found in the cytoplasm and the specializations of the membrane. Clearly, the cell is capable of sorting material, transporting some organelles (such as ribosomes) into dendrites but not axons. Since microtubules play a crucial role in intracellular transport processes and since the microtubules in axons and dendrites are so different, it seems possible that the differences in microtubules may provide a means for the sorting of material to be transported (see Matus et al., 1981). For example, it is possible that material destined for transport into dendrites but not axons would have some specific "label" which would permit the material to recognize dendritic microtubules by their complement of microtubule-associated proteins. Similarly, material destined for axons and not for dendrites might recognize axonal microtubules, either because of the presence of other microtubule-associated proteins or by the low concentrations of MAP2. In this way, neurons could sort out material and organelles destined specifically for axons and dendrites within the cell body. One could image that this sort of "labeling" would be particularly important during the formation of the different types of processes, where spatial cues may be absent or not well developed. In this regard, it is of interest that Bernhart and Matus (1982) report that HMW-MAP immunoreactivity appears in dendrites before tubulin. Whatever the functional significance of the differences between microtubules in axons and dendrites, it seems likely that such dramatic differences will be of considerable significance for the operation of the microtubules. The elucidation of these functional differences between microtubles will likely provide us with important new insights into how neurons regulate their form and thus their functional properties.

\section{References}

Bender, P. C. (1981) Microtubule associated proteins. Ph.D. thesis, University of Virginia, Charlottesville.

Bender, P. C., D. C. Benjamin, and L. I. Rebhun (1982) Analysis of the relationship of bovine HMW2 and Tau using radioimmune assay. Biochim. Biophys. Acta 708: 149-159.

Bernhardt, R., and A. Matus (1982) Initial phase of dendritic growth: Evidence for the involvement of high molecular weight microtubule-associated proteins (HMWP) before the appearance of tubulin. J. Cell Biol. 92: 589-593.

Binder, L. I., M. R. Payne, H. Kim, V. R. Sheridan, D. K. Schroeder, C. C. Walker, and L. I. Rebhun (1982) Production and analysis of monoclonal antibodies specific for beta-tubulin and MAP2. J. Cell Biol. 95: 3490.

Caceres, A., P. Bender, and O. Steward (1982a) Differential intracellular localization of cytoskeletal proteins in neurons of rat hippocampus as revealcd by immunocytochemistry. Anat. Rec. 202: 24A.

Caceres, A., M. R. Payne, and O. Steward (1982b) Localization of actin in neuronal dendrites and their spines. J. Cell Biol. 95: 285a.

Caceres, A., M. R. Payne, L. I. Binder, and O. Steward (1983a) Immunocytochemical localization of actin and microtubule associated protein (MAP2) in dendritic spines. Proc. Natl. Acad. Sci. U. S. A. 80: 1738-1742.
Caceres, A., P. Bender, L. Snavely, L. Rebhun, and O. Steward (1983b) Distribution and subcellular localization of calmodulin in adult and developing brain tissue. Neuroscience 10 : 449-461.

Cotman, C. W., and P. T. Kelly (1980) Macromolecular architecture of C.N.S. synapses. In The Cell Surface and Neuronal Function, C. W. Cotman, G. Post, and G. L. Nicholson, eds., pp. 505-533, Elsevier North Holland Biomedical Press, Amsterdam.

Gozes, I., and C. J. Barnstable (1982) Monoclonal antibodies that recognize discrete forms of tubulin. Proc. Natl. Acad. Sci. U. S. A. 79: 2579-2583.

Gozes, I., and K. J. Sweadner (1981) Multiple tubulin forms are expressed by a single neuron. Nature 294: 477-479.

Gray, E. G. (1959) Axosomatic and axodendritic synapses of the cerebral cortex: An electron microscopic study. J. Anat. 93: $420-423$.

Gray, E. G., L. E. Westrum, R. D. Burgoyne, and J. Barron (1982) Synaptic organization and neuron microtubule distribution. Cell Tissue Res. 226: 579-588.

Griffith, L., and T. D. Pollard (1982) The interaction of actin filaments with microtubules and microtubule associated proteins. J. Biol. Chem. 257: 9143-9152.

Izant, J. G., and J. R. McIntosh (1980) Microtubules associated proteins: A monoclonal antibody to MAP2 binds to differentiated neurons. Proc. Natl. Acad. Sci. U. S. A. 77: 47414745 .

Kim, H., L. I. Binder, and J. L. Rosenbaum (1979) The periodic association of MAP2 with brain microtubules in vitro. J. Cell Biol. 80: 266-276.

Kohler, G., and C. Milstein (1976) Derivation of specific antibody-producing tissue culture and tumour cell lines by cell fusion. Eur. J. Immunol. 6: 511-519.

Kreutzberg, G. W. (1981) Parameters of dendritic transport. Neurosci. Res. Program Bull. 20: 45-55.

Laemmli, U. K. (1970) Cleavage of structural proteins during the assembly of the head of bacteriophage $T_{4}$. Nature (Lond.) 227: 680 .

Lasek, R. J. (1981) The dynamic ordering of neuronal cytoskeleton. Neurosci. Res. Program Bull. 19: 7-31.

Matus, A., R. Bernhardt, and T. H. Jones (1981) High molecular weight microtubules-associated proteins are preferentially associated with dendritic microtubules in brain. Proc. Natl. Acad. Sci. U. S. A. 78: 3010-3014.

Oi, V. T., and L. A. Herzenberg (1980) Immunoglobulin producing hybrid cell lines. In Selected Methods in Cellular Immunology, B. B. Mishell and S. M. Shiigi, eds., pp. 351372, W. H. Freeman, San Francisco.

Payne, M. R. (1983) Monoclonal antibodies to the contractile proteins. In Cell and Muscle Motility, Ed. 4, R. Dowben and J. Shay, eds., pp. 137-177, Plenum Press, New York.

Peters, A., S. Palay, and H. de F. Webster (1976) The Fine Structure of the Nervous System, W. B. Saunders Co., Philadelphia.

Rall, W., and J. Rinzel (1973) Branch input resistance and steady attenuation for input to one branch of a dendritic neuron model. Biophys. J. 13: 648-687.

Shulman, M., C. D. Wilde, and G. Kohler (1978) A better line for making hybridomas secreting specific antibodies. Nature 276: $269-270$.

Sloboda, R. D., S. A. Rudolph, J. L. Rosenbaum, and P. Greengard (1975) Cyclic AMP dependent endogenous phosphorylation of a microtubule associated protein. Proc. Natl. Acad. Sci. U. S. A. 72: 177-181.

Solomon, F. (1981) Specification of cell morphology by endogenous determinants. J. Cell Biol. 90: 547-553.

Solomon, F., and M. Magendantz (1981) Cytochalasin sepa- 
rates microtubule disassembly from loss of asymmetric morphology. J. Cell Biol. 89: 157-161.

Sternberger, L. A. (1979) Immunocytochemistry, Wiley, New York.

Towbin, H., T. Staehelin, and J. Gordon (1979) Electrophoretic transfer of protein from polyacrylamide gels to nitrocellulose sheets: Procedure and some application. Proc. Natl. Acad. Sci. U. S. A. 76: 4354-4356.

Vallee, R. B. (1982) A taxol dependent procedure for the isolation of microtubules and microtubules associated pro- teins (MAPs). J. Cell Biol. 92: 435-442.

Vallee, R. B., M. J. DiBartolomeis, and W. E. Theurkauf (1981) A protein kinase bound to the projection portion of MAP2 (microtubule-associated protein 2). J. Cell Biol. 90: 568-576.

Westrum, L. E., D. H. Jones, E. G. Gray, and J. Barron (1980) Microtubules, dendritic spines and spine apparatuses. Cell Tissue Res. 208: 171-181.

Weingarten, M. D., A. H. Lockwood, S. Y. Hwo, and M. W. Kirschner (1975) A protein factor essential for microtubule assembly. Proc. Natl. Acad. Sci. U. S. A. 72: 1858-1862. 